J. Clin. Chem. Clin. Biochem.

Vol. 28, 1990, pp. 233-240

(C) 1990 Walter de Gruyter \& Co. Berlin $\cdot$ New York

\title{
A New Development in Haematological Cell Counting: The Sysmex NE-8000, Automaton for Cell Count and Physical Five-Part Leukocyte Differentiation
}

\author{
By $J . W . J$. van Wersch and C. Bank \\ Haematological Laboratory, De Wever Hospital, Heerlen, The Netherlands
}

(Received September 25, 1989/January 29, 1990)

\begin{abstract}
Summary: We compared the results of the Sysmex NE-8000 with those of the Sysmex E-4000 and the Technicon H-6000. Both for the whole blood cell count and the leukocyte differentiation we obtained intraand inter-assay coefficients of variation fully comparable with those for other cell counters.

The carry-over between samples was negligibly small. The linearity range was broad, which implies a universal application in routine haematological analysis. The numerical results from the Sysmex NE-8000 and the Technicon H-6000 corresponded closely, with exception of the mean corpuscular volume and the haematocrit, whereas these parameters showed excellent agreement between the NE-8000 and the E-4000. In the differentiation of leukocytes, the NE-8000 and H-6000 showed good correlation and conformity for lymphocytes, neutrophils and eosinophils; for monocytes and basophils the conformity was poor.
\end{abstract}

We also found a good correlation between the NE-8000 and E-4000 for lymphocytes and neutrophils, whereas the correlation was less for the middle cell ratio and the sum of monocytes, eosinophils and basophils.

Furthermore, we compared Receiver Operating Characteristic curves for the different leukocyte subtypes on the NE-8000, the H-6000 and the E-4000, and investigated the flagging frequency in inpatients, outpatients and blood donors.

\section{Introduction}

A rapid development has taken place in recent years in the field of cell counting and cell differentiation of peripheral blood cells $(1-3)$. The steadily increasing demand for analyses has stimulated the introduction of faster and more sophisticated machines.

The trend in instrumentation has been towards a combination of cell counting and cell differentiation in one apparatus. This may be based on flow cytochemical cytometry, or on impedance particle size measurement. The H-6000 (Technicon) is of the former type, whereas the Sysmex E-4000 is a three-part dif impedance cytometer. The E-4000 presents the leukocyte differentiation as a three-part differentiation on the basis of the volume distribution analysis of the white blood cells.
The discrimination of this so-called three-part dif cytometer in the analysis of the particle size of peripheral blood cells has now been improved, so that a five-part leukocyte differentiation, in addition to the usual parameters of the whole blood cell count, can be performed by a single machine, the Sysmex NE-8000.

The five-part dif results are actually reported as neutrophils, lymphocytes, eosinophils, basophils and monocytes. The Sysmex NE-8000 uses a combination of direct current and radio frequency measurement for the differentiation of the volume and the cell content (nucleus) of the leukocytes.

In order to test the capabilities and limitations of this automated cell counting and five-part cell differentiation machine, we compared the results of the Sysmex 
NE-8000 with those of the Sysmex E-4000 and the Technicon H-6000, the cytochemical flow cytometer. As a guideline for this investigation we used the protocol for the evaluation of automated blood cell counters as recommended by the International Committee for Standardization in Haematology (ICSH) (4).

\section{Materials and Methods}

\section{Materials}

We analysed in this study 513 samples from inpatients (52\%) and outpatients $(48 \%)$ without selection. The samples were drawn into EDTA-K $\mathrm{K}_{2}$-containing tubes (Sarstedt, FRG). In addition, we had at our disposal 150 blood samples from healthy blood donors from the Red Cross Blood Bank of Maastricht for reassessing the reference values for the new analyser (NE-8000)

Venous blood $(5 \mathrm{ml})$ was collected in vials containing $7.5 \mathrm{mg}$ EDTA-Na $a_{2}$ (Venoject). The samples were kept at room temperature for maximally 5 hours before they were run on the Sysmex NE-8000 (Toa Medical Electronics Corp., Kobe, Japan).

\section{Apparatus}

We tested the new Sysmex NE-8000 (Toa Medical Electronics Corp., Kobe, Japan) against the Technicon H-6000 (Technicon Instruments Corp. Tarrytown, New York) and the Sysmex E4000 (Toa Medical Electronics Corp., Kobe, Japan). Each cytometer was in routine performance in our laboratory and was operated by experienced technicians.

The Technicon H-6000 was calibrated for the whole blood cell count daily, using the quadruplicate results of the Sysmex E4000 for a fresh sample from a proband with normal haematological results. All cytometers were used daily in the internal quality control programme.

\section{Data analysis}

The relation between the results from the Sysmex cytometers (NE-8000 and E-4000) and the Technicon H-6000 were calculated by orthogonal regression analysis according to Deming $(5,6)$. In addition, the Pearson rank correlation coefficient $(r)$ was calculated for the corresponding parameters. The significance of the differences between the mean results of the three cytometers was tested with Student's t-test. We assayed the analytical performance of the Sysmex NE- 8000 by calculating the sensitivity and specificity of the leukocyte subfractions against the results of the small cell ratio, middle cell ratio and the large cell ratio of the white blood cells of the Sysmex E4000 at rising decision limits of the three-part dif parameters, as well as against the five-part results of the Technicon H-6000.

\section{Results}

\section{Intra-assay precision}

The intra-assay CVs for the leukocyte formula could be determined only partially, owing to the absence of some of the subfractions (neutrophils, eosinophils) in the commercially available control samples. These CVs could only be determined with the aid of fresh samples. The results are given in table 1 . Average $\mathrm{CVs}$ were $2.5 \%$ (neutrophils), $2.0 \%$ (lymphocytes), $16.5 \%$ (monocytes), $10.0 \%$ (eosinophils) and $45.6 \%$ (basophils).

\section{Accuracy}

The results of the accuracy test are also given in table 1. The results are presented as percentage recovery according to the assigned values of the commercially

Tab. 1. Intra-assay precision, accuracy, linearity and carry-over of the NE-8000

\begin{tabular}{|c|c|c|c|c|c|}
\hline Parameter & & $\begin{array}{l}\text { Intra-assay } \\
\text { precision at } \\
\text { normal level } \\
(\mathrm{CV} \%)^{*}\end{array}$ & $\begin{array}{l}\text { Accuracy } \\
\text { at normal } \\
\text { level } \\
(\%)^{* *}\end{array}$ & $\begin{array}{l}\text { Linearity } \\
\text { tested } \\
\text { level }\end{array}$ & $\begin{array}{l}\text { Carry-over } \\
(\%)\end{array}$ \\
\hline White blood cell count & $\left(10^{9} / 1\right)$ & 2.2 & 100.0 & -60.2 & 0.95 \\
\hline Red blood cell count & $\left(10^{12} / 1\right)$ & 0.8 & 99.4 & $1.01-9.7$ & 0.22 \\
\hline Haemoglobin & $(\mathrm{mmol} / \mathrm{l})$ & 0.5 & 100.7 & $1.9-17.6$ & 0.21 \\
\hline Haematocrit & $(1 / 1)$ & 0.7 & 100.0 & $0.09-0.85$ & 0.26 \\
\hline Mean corpuscular volume & (fi) & 0.2 & 101.6 & & \\
\hline Mean corpuscular haemoglobin & (fmol) & 0.7 & 95.2 & & \\
\hline Mean corpuscular haemoglobin concentration & $(\mathrm{mmol} / \mathrm{l})$ & 0.6 & 119.0 & & \\
\hline Platelets & $\left(10^{9} / 1\right)$ & 1.9 & 102.7 & -964 & \\
\hline Red cell distribution width, CV & $(\%)$ & 0.4 & 99.3 & & \\
\hline Mean platelet volume & (f1) & 1.5 & 100.1 & & \\
\hline Neutrophilic granulocytes & $(\%)$ & 2.5 & 99.7 & & \\
\hline Lymphocytes & $(\%)$ & 2.0 & n.t. & & \\
\hline Monocytes & $(\%)$ & 16.5 & n.t. & & \\
\hline Eosinophils & $(\%)$ & 10.0 & 105.2 & & \\
\hline Basophils & $(\%)$ & 45.6 & 115 & & \\
\hline
\end{tabular}

* obtained in fresh blood sample, $\mathrm{N}=20$

** Eight-Check 923 WPCN, N $=20$

n. t. not tested 
available Eight Check 923 WPCN. Rather high recoveries (105.2 and 115\%) were found only for eosinophils and basophils.

\section{Linearity}

The samples for the linearity measurement of the leukocytes and platelets were prepared by diluting samples with high values with autologous plasma. Samples for the measurement of the haemoglobin and erythrocytes linearity were obtained by diluting packed cells with their own plasma. All determinations were carried out in duplicate. The results are given in table 1 . For leukocytes, linearity was found from zero up to $60.2 \times 10^{9} / 1$, for the erythrocytes from 1.01 to $9.7 \times 10^{12} / 1$, for platelets from zero to $964 \times 10^{9} / 1$ for the haemoglobin concentration from 1.9 to $17.6 \mathrm{mmol} / \mathrm{l}$.

\section{Carry-over}

The carry-over for the erythrocyte, leukocyte and platelet count was calculated from the equation:

$$
\text { carry-over }=\frac{A_{1}-A_{3}}{B_{3}-A_{3}} \times 100 \%
$$

For this purpose the high values were measured in triplicate $\left(B_{1}, B_{2}, B_{3}\right)$, followed by three measurements of the low values $\left(A_{1}, A_{2}, A_{3}\right)$. The carry-over for erythrocytes was $0.22 \%$, for leukocytes $0.95 \%$, for haemoglobin $0.21 \%$, and for the haematocrit $0.26 \%$ (tab. 1).

\section{Inter-assay variation}

The inter-assay variations of three different commercially available control blood samples are given in table 2. As can be seen, good results were obtained for the CVs for the whole blood cell count. The CVs for the platelet count at the lower level (59-67 $\left.\times 10^{9} / 1\right)$ and for the leukocyte count (level 1.9-4.3 $\left.\times 10^{9} / 1\right)$ were however somewhat higher, with values from $3.9-5.2 \%$ and about $2.9 \%$ and $3.2 \%$ respectively. The CVs for the leukocyte formula were nearly in the same range as those for the blood cell count, with exception of the monocytic, eosinophilic and basophilic series in the low normal range.

Comparison of the results from the Sysmex NE-8000 with those from the Technicon $\mathrm{H}-6000$

As can be seen from table 3, we obtained high coefficients of correlation for haemoglobin, haematocrit, erythrocytes and mean corpuscular haemoglobin, somewhat lower values for the mean corpuscular volume (0.92) and low values for mean corpuscular haemoglobin concentration and relative distribution width.

Tab. 2. Inter-assay variation of three different commercial blood samples assayed with the NE-8000, manual-mode, $\mathrm{N}=20$.

\begin{tabular}{|c|c|c|c|c|c|c|c|c|c|c|}
\hline & & \multicolumn{3}{|c|}{ N-Level ${ }^{1}$ ) } & \multicolumn{3}{|c|}{ L-Level²) } & \multicolumn{3}{|c|}{ NE Check- $\mathrm{L}^{3}$ ) } \\
\hline & & $\overline{\mathrm{x}}$ & $\mathrm{SD}$ & $\begin{array}{l}\text { CV } \\
\%\end{array}$ & $\overline{\mathrm{x}}$ & SD & $\begin{array}{l}\text { CV } \\
\%\end{array}$ & $\overline{\mathrm{x}}$ & $\mathrm{SD}$ & $\begin{array}{l}\text { CV } \\
\%\end{array}$ \\
\hline White blood cell count & $\left(10^{9} / 1\right)$ & 4.34 & 0.115 & 2.6 & 1.88 & 0.055 & 2.9 & 2.51 & 0.081 & 3.2 \\
\hline Red blood cell count & $\left(10^{12} / 1\right)$ & 4.92 & 0.028 & 0.6 & 2.20 & 0.015 & 0.7 & 2.64 & 0.017 & 0.6 \\
\hline Haemoglobin & $(\mathrm{mmol} / \mathrm{l})$ & 9.7 & 0.08 & 0.8 & 3.8 & 0.03 & 0.8 & 4.2 & 0.04 & 1.0 \\
\hline Haematocrit & $(1 / 1)$ & 0.44 & 0.003 & 0.7 & 0.18 & 0.001 & 0.7 & 0.21 & 0.002 & 1.0 \\
\hline Mean corpuscular volume & (fl) & 90.1 & 0.32 & 0.4 & 81.4 & 0.38 & 0.5 & 78.1 & 0.75 & 1.0 \\
\hline Mean corpuscular haemoglobin & $(\mathrm{fmol})$ & 1.97 & 0.019 & 1.0 & 1.73 & 0.017 & 1.0 & 1.60 & 0.015 & 1.0 \\
\hline Mean corpuscular haemoglobin concentration & $(\mathrm{mmol} / \mathrm{l})$ & 21.9 & 0.25 & 1.1 & 21.3 & 0.23 & 1.1 & 20.5 & 0.22 & 1.1 \\
\hline Platelets & $\left(10^{9} / 1\right)$ & 224 & 5.3 & 2.4 & 59 & 3.1 & 5.2 & 67 & 2.6 & 3.9 \\
\hline Red cell distribution width, SD & (fl) & 45.0 & 0.32 & 0.7 & 41.6 & 0.27 & 0.7 & 43.7 & 0.37 & 0.9 \\
\hline Red cell distribution width, $\mathrm{CV}$ & $(\%)$ & 13.8 & 0.11 & 0.8 & 14.2 & 0.13 & 0.9 & 15.7 & 0.21 & 1.3 \\
\hline Platelet distribution width & (fl) & 10.2 & 0.19 & 1.9 & 9.7 & 0.44 & 4.5 & 8.6 & 0.31 & 3.6 \\
\hline Mean platelet volume & (fl) & 9.3 & 0.10 & 1.1 & 8.9 & 0.19 & 2.1 & 10.0 & 0.25 & 2.5 \\
\hline Neutrophilic granulocytes & $(\%)$ & 90.0 & 1.48 & 1.6 & 90.8 & 1.30 & 1.4 & 69.3 & 2.22 & 3.2 \\
\hline Lymphocytes & $(\%)$ & - & - & - & - & - & - & 22.7 & 4.24 & 18.6 \\
\hline Monocytes & $(\%)$ & - & - & - & - & - & - & 8.0 & 2.31 & 28.9 \\
\hline Eosinophils & $(\%)$ & 114.8 & 3.29 & 2.9 & 118.0 & 4.78 & 4.0 & 68.9 & 3.27 & 4.7 \\
\hline Basophils & $(\%)$ & 96.0 & 3.31 & 3.4 & 100.1 & 4.09 & 4.1 & 104.3 & 4.42 & 4.2 \\
\hline
\end{tabular}

1) Normal level control, Eight-check $923 \mathrm{WPCN}$

$\left.{ }^{2}\right)$ Low level control, Eight-check 923 WPL

3) NE Check-L (prototype III)

- results not displayed 
Tab. 3. Comparison of the results of the sysmex NE-8000 and Technicon H-6000 $(\mathrm{N}=513)$

\begin{tabular}{|c|c|c|c|c|}
\hline \multirow[t]{2}{*}{ Parameter } & & \multicolumn{2}{|c|}{ Regression } & \multirow{2}{*}{$\begin{array}{l}\text { Correlation } \\
\text { coefficient } \\
\mathrm{r}^{* *}\end{array}$} \\
\hline & & + & $b x^{*}$ & \\
\hline White blood cell count & $\left(10^{9} / 1\right)$ & -0.917 & 1.062 & 0.990 \\
\hline Red blood cell count & $\left(10^{12} / 1\right)$ & -0.020 & 1.000 & 0.990 \\
\hline Haemoglobin & $(\mathrm{mmol} / \mathrm{l})$ & 0.455 & 0.966 & 0.994 \\
\hline Haematocrit & $(1 / 1)$ & 0.010 & 1.000 & 0.975 \\
\hline Mean corpuscular volume & (fl) & -11.608 & 1.163 & 0.923 \\
\hline Mean corpuscular haemoglobin & (fmol) & -0.050 & 1.050 & 0.959 \\
\hline Mean corpuscular haemoglobin concentration & $(\mathrm{mmol} / \mathrm{l})$ & -3.238 & 1.154 & 0.388 \\
\hline Platelets & $\left(10^{9} / 1\right)$ & -7.776 & 0.965 & 0.980 \\
\hline Red cell distribution width, SD & (f1) & -11.096 & 3.52 & 0.321 \\
\hline Red cell distribution width, CV & $(\%)$ & -2.022 & 0.984 & 0.726 \\
\hline Platelet distribution width & (fl) & -6.483 & 0.414 & 0.199 \\
\hline Mean platelet volume & (f1) & -1.333 & 1.443 & 0.405 \\
\hline Neutrophilic granulocytes & $(\%)$ & 2.100 & 0.980 & 0.980 \\
\hline Lymphocytes & $(\%)$ & -0.909 & 0.984 & 0.992 \\
\hline Monocytes & $(\%)$ & 1.983 & 0.810 & 0.460 \\
\hline Eosinophils & $(\%)$ & -0.031 & 1.086 & 0.976 \\
\hline Basophils & $(\%)$ & 0.160 & 1.200 & 0.572 \\
\hline
\end{tabular}

* Orthogonal regression of $y=a x+b ; y=$ results NE-8000, $x=$ results $\mathrm{H}-6000$.

** All Pearson correlation coefficients were significant $(p<0.001)$.

The good correlation is limited to the range between 75 and 99 fl. The results for the platelets and white blood cell series yielded noticeably high correlation coefficients for platelets, leukocytes, neutrophils, lymphocytes and eosinophils $(0.98,0.99,0.98,0.99$ and 0.98 respectively), whereas moderate correlations were found for the monocytic and basophilic count $(0.46$ and 0.57 ).

Comparison of the results from the Sysmex NE-8000 with those from the Sysmex E-4000

Table 4 shows the results for the three cell series. The coefficients of correlation for the erythrocytic parameters are in general high, i. e. 0.99 for the erythrocyte count, 0.98 for the mean corpuscular volume, 0.87 for the mean corpuscular haemoglobin concentration and 0.95 for red cell distribution width.

For the platelet and leukocyte series we again found good correlations, with correlation coefficients for platelets, leukocytes and lymphocytes of $0.99,0.99$ and 0.99 , whereas the correlation for the neutrophils amounted 0.93 , and that for the sum of the monocytes, eosinophils and basophils (MEB-fraction) was 0.60 .

Dif screening ability of the Sysmex NE- 8000

The Sysmex NE-8000 offers a flagging facility, which indicates "suspect for" immature granulocytes, left shift, blasts, atypical lymphocytes. On the basis of

Tab. 4. Comparison of the results of the Sysmex NE-8000 and the Sysmex E-4000 (N = 513)

\begin{tabular}{|c|c|c|c|c|}
\hline \multirow[t]{2}{*}{ Parameter } & & \multicolumn{2}{|c|}{ Regression } & \multirow{2}{*}{$\begin{array}{l}\text { Correlation } \\
\text { coefficient } \\
\mathrm{r}^{* *}\end{array}$} \\
\hline & & + & $b x^{*}$ & \\
\hline White blood cell count & $\left(10^{9} / 1\right)$ & 0.506 & 0.895 & 0.991 \\
\hline Red blood cell count & $\left(10^{12} / 1\right)$ & 0.044 & 0.990 & 0.996 \\
\hline Haemoglobin & $(\mathrm{mmol} / \mathrm{l})$ & 0.200 & 1.000 & 0.996 \\
\hline Haematocrit & $(1 / 1)$ & 0.000 & 1.000 & 0.995 \\
\hline Mean corpuscular volume & (fl) & -0.113 & 1.005 & 0.995 \\
\hline Mean corpuscular haemoglobin & (fmol) & 0.020 & 1.000 & 0.984 \\
\hline Mean corpuscular haemoglobin concentration & $(\mathrm{mmol} / \mathrm{l})$ & 2.210 & 0.900 & 0.871 \\
\hline Platelets & $\left(10^{9} / 1\right)$ & 19.27 & 0.892 & 0.995 \\
\hline Red cell distribution width, CV & $(\%)$ & 0.072 & 1.029 & 0.948 \\
\hline Mean platelet volume & (fl) & -0.086 & 1.018 & 0.936 \\
\hline Neutrophilic granulocytes & $(\%)$ & 4.646 & 0.923 & 0.925 \\
\hline Sum of the monocytes, eosinophils and basophils & $(\%)$ & 3.025 & 0.675 & 0.598 \\
\hline Lymphocytes & $(\%)$ & 1.623 & 0.850 & 0.985 \\
\hline
\end{tabular}

* Orthogonal regression of results of the Sysmex NE-8000 and the Sysmex E-4000 (N = 513)

** All Pearson correlation coefficients were significant $(\mathrm{p}<0.001)$. 
these signals we investigated a population of inpatients and outpatients as well as a blood donor group.

The results are given in table 5 . As can be seen, $68 \%$ of the samples showed none of the above mentioned flagging signals. From the $32 \%$ samples with the indication "suspect for", the flags can be subdivided in $13.6 \%$ immature granulocytes, $12.3 \%$ left shift, $9.6 \%$ blasts and $0.2 \%$ atypical lymphocytes. As could be expected, the number of samples flagged in the blood donor group was very low ( $2 \%$ of all samples). In table 6 the results are given for the frequency and the distribution of the NE-8000 "red suspect flags"; only $1.2 \%$ are indicated in blood donors and $12.9 \%$ in patients. With respect to the distribution of the flags, the highest percentage is seen for the "platelet clumps" signal ( $7.8 \%$ in the patient group versus $1.2 \%$ in the donor group).

\section{Receiver Operating Characteristic (ROC) curves}

In order to obtain an objective insight into the analytical performance of the NE-8000 differential count, we used the results to compute the sensitivity and specificity for the leukocyte subfractions (neutrophils, lymphocytes and the sum of the monocytes, eosinophils, and basophils) at rising limits of the five-part differentiation parameters against those of the Sysmex E-4000 (fig. 1) and against those of the Technicon $\mathrm{H}$ -

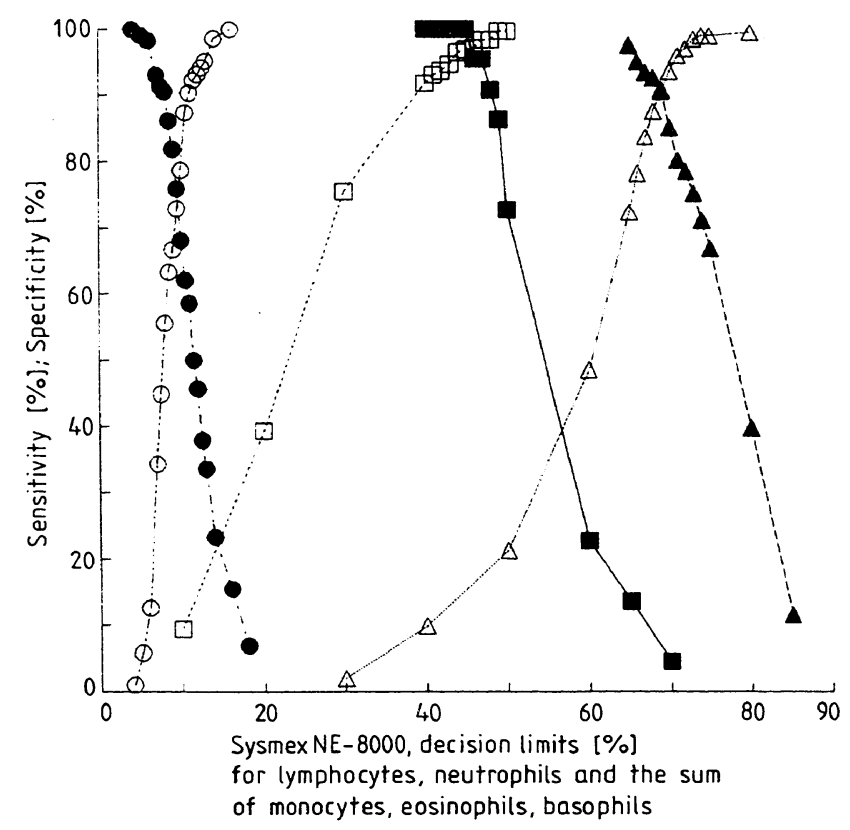

Fig. 1. Sensitivity (closed symbols) and specificity (open symbols) of the NE-8000 for lymphocytes $(\mathbf{\square}, \square)$, neutrophils $(\boldsymbol{\Delta}, \triangle)$ and the monocytes, eosinophils, basophils (MEB) fraction $(\bullet, 0)$, calculated on the basis of the following E-4000 decision limits: lymphocytes $>50.0 \%$, neutrophils $>70.0 \%$ and the MEB fraction $>10.0 \%$.
Tab. 5. Frequency and distribution of the NE- 8000 "white suspect flag" in patients and blood donors

\begin{tabular}{|c|c|c|c|}
\hline Parameter & & Patients & Donors \\
\hline Whithout flag & $(\%)$ & 67.8 & 98.3 \\
\hline With flag & $(\%)$ & 32.2 & 1.8 \\
\hline \multirow[t]{2}{*}{ Parameters } & & \multicolumn{2}{|c|}{$\begin{array}{l}\text { Distribution } \\
\text { of the flags }\end{array}$} \\
\hline & & Patients & Donors \\
\hline Left shift & $(\%)$ & 12.3 & 1.2 \\
\hline Immature granula & $(\%)$ & 13.6 & - \\
\hline Blasts & $(\%)$ & 9.6 & 0.6 \\
\hline Atypical lymphocytes & $(\%)$ & 0.2 & - \\
\hline
\end{tabular}

* 18 patients with two suspect white flaggings

Tab. 6. Frequency and distribution of the NE-8000 "red suspect flag" in patients and blood donors

\begin{tabular}{|c|c|c|c|}
\hline Parameter & & $\begin{array}{l}\mathrm{Pa}- \\
\text { tients }\end{array}$ & $\begin{array}{l}\text { Do- } \\
\text { nors }\end{array}$ \\
\hline Without flag & $(\%)$ & 87.1 & 98.8 \\
\hline With flag & $(\%)$ & 12.9 & 1.2 \\
\hline \multirow[t]{2}{*}{ Parameter } & & \multicolumn{2}{|c|}{$\begin{array}{l}\text { Distribution } \\
\text { of the flags }\end{array}$} \\
\hline & & $\begin{array}{l}\mathrm{Pa}- \\
\text { tients }\end{array}$ & $\begin{array}{l}\text { Do- } \\
\text { nors }\end{array}$ \\
\hline Red blood cell count agglutination & $(\%)$ & - & - \\
\hline Poikilocytosis & $(\%)$ & - & - \\
\hline Iron deficiency & $(\%)$ & 2.3 & - \\
\hline Haemoglobin defect & $(\%)$ & 0.6 & - \\
\hline Lipaemia & $(\%)$ & 0.2 & - \\
\hline Large platelet/micro red blood cell count & $(\%)$ & 1.9 & - \\
\hline Fragments & $(\%)$ & - & - \\
\hline Nucleated red blood cells & $(\%)$ & - & - \\
\hline Large platelet & $(\%)$ & 1.0 & - \\
\hline Small platelet & $(\%)$ & - & - \\
\hline Platelet clumps & $(\%)$ & 7.8 & 1.2 \\
\hline Micro red blood cell count & $(\%)$ & - & - \\
\hline
\end{tabular}

* 5 patients with two suspect flaggings

6000 (fig. 2 and 3). From figure 1 we can see that on the basis of the E-4000 cut-off levels (lymphocytes $50 \%$, neutrophils $70 \%$ and MEBs $10 \%$ ) the lymphocytes count reached an equal sensitivity/specificity of $97 \%$ at the decision limit of $47 \%$ on the NE- 8000 . The neutrophil count reached a somewhat lower peak for the sensitivity/specificity of $90 \%$ at the decision limit of $70 \%$. The maximal sensitivity/specificity for the MEB fraction amounted $75 \%$ at the decision level of $10 \%$. Figure 2 shows that in relation to the $\mathrm{H}$ 6000 cut-off levels (lymphocytes 50\%, neutrophils $70 \%$, monocytes $8 \%$, eosinophils $5 \%$, basophils $2 \%$ ) the sensitivity/specificity reaches a maximum of $97 \%$ for the lymphocytes at the decision level of $43 \%$, and a maximum of $92 \%$ for the neutrophils at the decision 


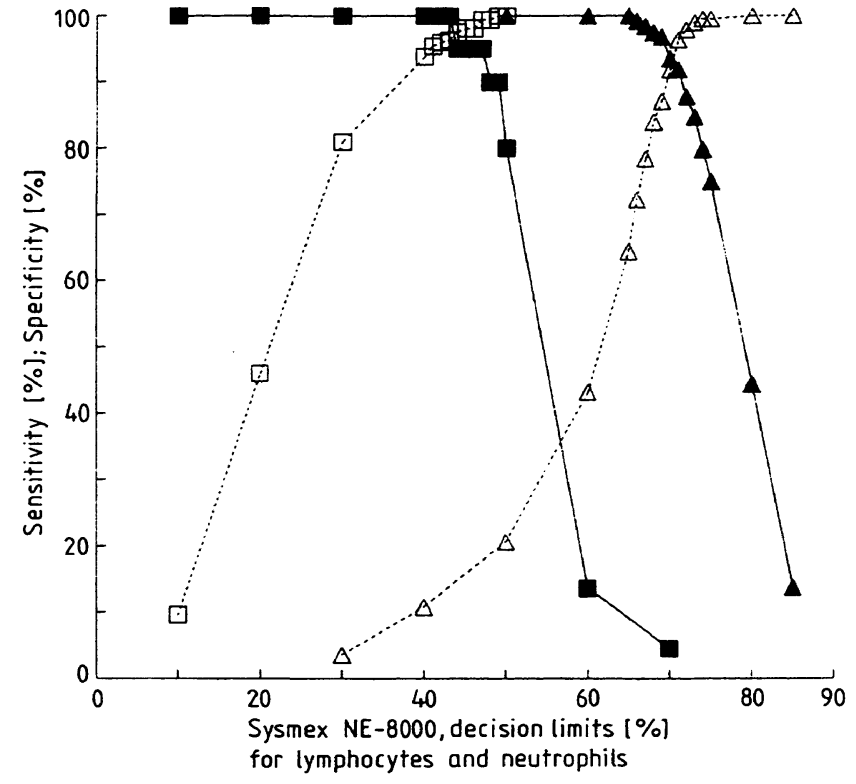

Fig. 2. Sensitivity (closed symbols) and specificity (open symbols) of the NE-8000 for lymphocytes $(\square, \square)$, neutrophils $(\Delta, \Delta)$ calculated on the basis of the following H-6000 decision limits: lymphocytes $>50.0 \%$, neutrophils $>70.0 \%$.

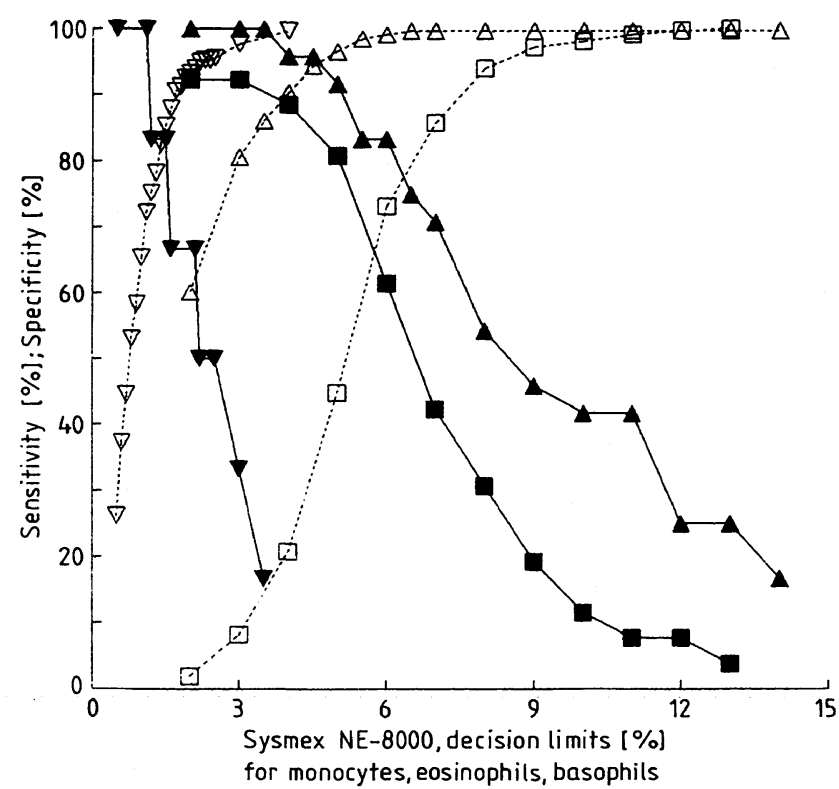

Fig. 3. Sensitivity (closed symbols) and specificity (open symbols) of the NE-8000 for monocytes $(\square, \square)$, eosinophils $(\boldsymbol{\Lambda}, \triangle)$ and basophils $(\boldsymbol{\nabla}, \nabla)$ calculated on the basis of the following H-6000 decision limits: monocytes $>8.0 \%$, eosinophils $>5.0 \%$ and basophils $>2.0 \%$.

limit of $70 \%$, whereas the sensitivity/specificity peaks were located at $6 \%$ for the monocytes (peak of $67 \%$ ), at $4.8 \%$ for the eosinophils (peak of $94 \%$ ) and at $1.5 \%$ for the basophils (peak of $83 \%$ ) (fig. 3 ).

\section{Reference values}

Table 7 shows the the reference values on the Sysmex NE-8000 for males and females, both for the whole blood cell count and for the leukocyte differentiation.

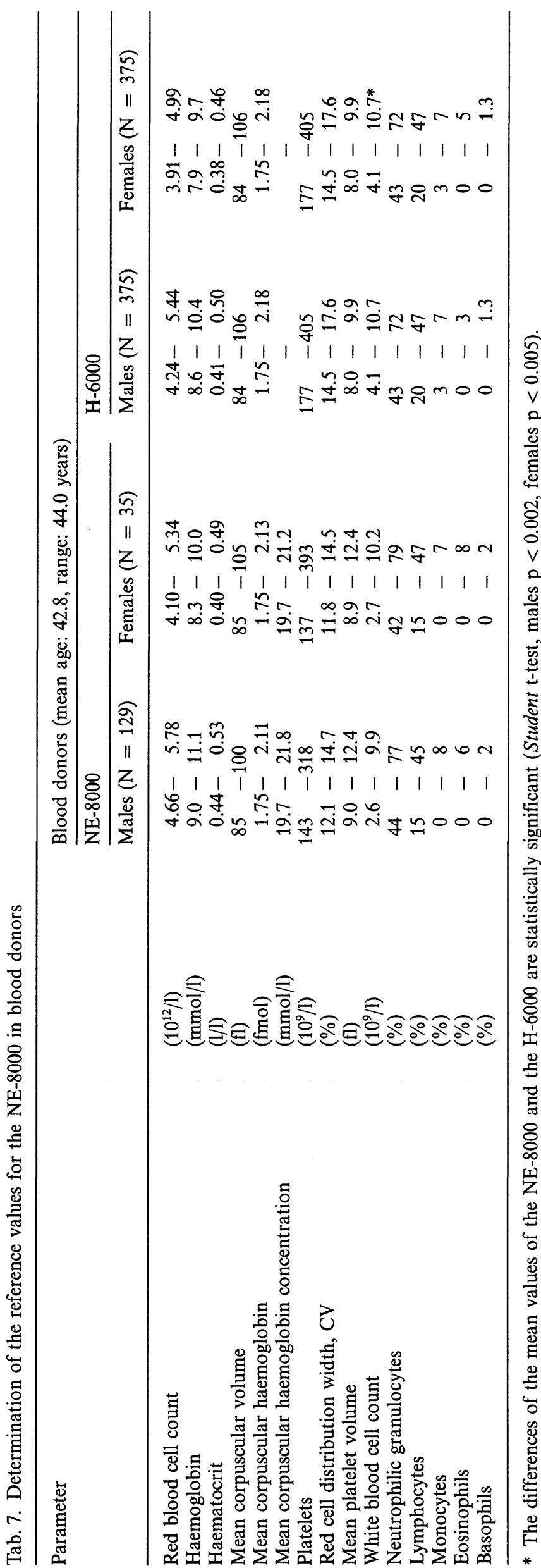


In general, the values are comparable with those obtained with the Technicon H-6000. This is especially important for the reference values of the monocytic, eosinophilic and basophilic series, which are the new parameters in the recently introduced Sysmex NE8000. Little difference can be seen for the lower limit of the lymphocyte count ( 15 vs. $20 \%$ ). Noticeable is the somewhat lower reference range for the NE- 8000 leukocyte count in comparison with the results from the $\mathrm{H}-6000$.

\section{Discussion}

The newly introduced Sysmex NE-8000 is designed for whole blood cell counting and for five-part leukocyte differentiation. We were interested in the analytical capabilities and in the performance of this socalled five-part differentiation with that of the Technicon H-6000 and the Sysmex E-4000, both of which are routinely in use in our laboratory. The intra- and inter-assay variations of the Sysmex NE-8000 were good and showed correlation coefficients fully comparable with those for other blood cell counters $(7-10)$. The carry-over was negligible. The linearity range was so broad as to be universally useful in routine haematological analysis for all cell lines. The numerical results of the Sysmex NE-8000 and the Technicon H-6000 compare well, with exception of the mean corpuscular volume and the haematocrit, and consequently the mean corpuscular haemoglobin concentration.

Both in the lower mean corpuscular volume region $(<75 \mathrm{fl})$ and the higher mean corpuscular volume ( $>100 \mathrm{fl}$ ), the mean corpuscular volume values on the NE-8000 are higher than in the Technicon $\mathrm{H}$ 6000 . This difference was not found in the comparison of the mean corpuscular volume results on Sysmex NE-8000 and Sysmex E-4000.

This type of a discrepancy has already been reported and discussed (11) in our comparison of the Sysmex E-4000 and the Technicon H-6000. We can conclude again that the performance of both types of instrument is problematic as far as erythrocyte volume measurement is concerned. The numerical results of the Sysmex NE-8000 and the Sysmex E-4000 showed excellent agreement. The leukocyte differentiation showed good correlations between the Sysmex NE8000 and the Technicon H-6000 for the lymphocytes, neutrophils and eosinophils, whereas the conformity between the monocytes and basophils was poor. The same pattern was found after comparison of the Sysmex NE-8000 and the Sysmex E-4000. Good correlation and conformity were found for the lympho- cytes/small cell ratio and neutrophils/large cell ratio, but the correlation for the sum of the monocytes, eosinophils and basophils of the Sysmex NE-8000 and the middle cell ratio of the Sysmex E-4000 was relatively poor. We found not only excellent agreement between the lymphocytes (NE-8000) and the small cell ratio of the Sysmex E-4000, but also high sensitivity and specificity (max. $87 \%$ at $47 \%$ cut-off level) when comparing the Sysmex NE-8000 and the Sysmex E-4000 for their ability to discriminate normal from abnormal lymphocyte rates as assayed by the Sysmex E-4000.

The neutrophilic rates of the Sysmex NE-8000 represented a high sensitivity for increased rates of neutrophils, as well as good confirmity with the large cell ratio of the Sysmex E-4000. The sensitivity/specificity reached maximally $90 \%$ at the cut-off level of $70 \%$. The enumeration of the Sysmex NE- 8000 monocytes, eosinophils and basophils correlated significantly with the middle cell ratio of the Sysmex E4000; the performance of this summed leukocyte fraction is poor with a maximal sensitivity/specificity value of $75 \%$ at a decision limit of $10 \%$. ROC curves constructed for the NE-8000 with the $\mathrm{H}-6000$ as a reference revealed high peaks for the sensitivity/specificity point of interception for the neutrophils $(92 \%)$, lymphocytes (97\%) and the eosinophils $(94 \%)$ at decision levels respectively of $70 \%, 43 \%$ and $4.8 \%$. The results for the basophils were also satisfactory (peak of $83 \%$ at $15 \%$ cut-off level).

The monocytic peak sensitivity/specificity was rather low with a peak height of $67 \%$ at a cut-off level of $6 \%$. The occurrence of flagging on the Sysmex NE8000 is based upon analysis of the leukocyte histogram. The software of the leukocyte histogram analysis provides a number of "abnormal flaggings" based upon the numerical counts, together with the following 4 "suspect flaggings" based solely on the leukocyte histogram analysis: blasts, immature granulocytes, left shift and atypical lymphocytes. Our finding was that the flagging frequency of the NE- 8000 amounted to about $30 \%$ in a nearly equally mixed population of inpatients and outpatients. The flagging could be subdivided into $9.6 \%$ blasts, $12.3 \%$ left shift, $13.6 \%$ immature granulocytes and $0.2 \%$ atypical lymphocytes.

A very low incidence of flagging was anticipated amongst the blood donors, and this was indeed the case. These findings, especially for the leukocyte differentiation, provide further evidence for the good differentiation capability of the new Sysmex NE-8000. Although differences between the Sysmex NE- 8000 and the Technicon H-6000 were found only in some reference parameters for the cell count and cell dif- 
ferentiation, the deviations were nevertheless of such a magnitude that every laboratory should reassess its own reference values when it introduces the Sysmex NE-8000.

In conclusion, the Sysmex NE-8000 showed good performance characteristics for the whole blood cell count, compared with the Technicon $\mathrm{H}-6000$ and the Sysmex E-4000. Although the red blood cell parameters agreed very well, caution should be exercised with respect to those parameters based upon volume measurement, because there were considerable differences in the mean corpuscular volume measurements

\section{References}

1. Van Wersch, J. W. J. (1987) Neue Entwicklungen im hämatologischen Notfall-Labor. In: Das Notfall-Labor, Organisation und Management (Henkel, E., ed.) GIT Verlag GmbH (Darmstadt), pp. 38-44.

2. Lombarts, A. J. P. F., Koevoet, A. L. \& Leijnse, B. (1986) Basic principles and problems of haemocytometry. Ann. Clin. Biochem. 23, 390-404.

3. Williams, L. J. (1984) Cell histograms: New trends in data interpretation and cell classification. J. Med. Technol. 1, $189-196$.

4. International Committee for Standardization in Haematology (ICSH); Protocol for evaluation of automated blood cell counters (1984). Clin. Lab. Haemat. 6, 69-84.

5. Cornbleet, P. J. \& Gochman, N. (1979) Incorrect leastsquases regression coefficients in method-comparison analysis. Clin. Chem. 25, 432-438.

6. Deming, W. E. (1943) Statistical Adjustment of Data. John Wiley and Sons, New York, p. 184. on the two types of instrument. In the leukocyte formula the Sysmex NE-8000 and the Technicon $\mathrm{H}$ 6000 showed excellent agreement for the neutrophils, lymphocytes and eosinophils. The monocytic and basophilic series showed lower correlation and conformity.

The question remains as to which apparatus delivers the correct results, since there is no gold standard for these parameters. Nevertheless, the use of the Sysmex NE-8000 for white blood cell differentiation serves well for the identification of those samples that need microscopic examination.

7. Nelson, L., Charache, S., Wingfield, S. \& Keyser, E. (1988) Laboratory evaluation of differential white blood cell count information from the Coulter S-Plus IV and the Technicon $\mathrm{H}-1$ in patient populations requiring rapid "turnaround" time. Am. J. Clin. Pathol. 91, 563-569.

8. Tisdall, P. A. (1985) Evaluation of a laser-based three-part leucocyte differential analyser in detection of clinical abnormalities. Lab. Med. 16, 228-233.

9. Nelson, L., Charache, S., Keyser, E. \& Metzger, P. (1985) Laboratory evaluation of the Coulter "three-part" electronic differential. Am. J. Clin. Pathol. 83, 547-554.

10. Bollinger, P. B., Drewinko, B., Brailas, C. D., Smeeton, N. A. \& Trujillo, J. M. (1987) The Technicon H-1 an automated hematology analyzer for today and tomorrow. Am. J. Clin. Pathol. 87, 71-78.

11. Smeets, E. H. J. \& van Wersch, J. W. J. (1988) Performance of a three-part dif impedance cytometer (Sysmex E-4000) in comparison with a cytochemical cytometer (Technicon H-6000). J. Clin. Chem. Clin. Biochem. 26, 531-540.

Dr. J. W. J. van Wersch De Wever Ziekenhuis Haematologisch Laboratorium Postbus 4446 NL-6401 CX Heerlen 